\title{
Impact of Socio-Economic Characteristics on Food Insecurity Status: Evidence from Rural Households in Sri Lanka
}

\author{
K. K. H. M. Rathnayake*, P. Sivashankar and D. A. M De Silva
}

\begin{abstract}
Recent attention has been focused on means of eliminating food insecurity and hunger worldwide. Food security includes three dimensions, viz, availability, access and utilization. In the absence of any of these conditions, it can be considered as food insecurity. The aim of this study was to identify determinants of food insecurity status of rural households in Sri Lanka, using secondary data from a nationally representative sample data-set, the household income and expenditure survey of the Department of Census and Statistics. The analysis was carried out in two stages. In the first stage, the food insecurity index was determined and in the second stage ordered logistic regression model was executed to estimate the food insecurity status of the households as a function of a set of independent variables. The food insecurity index was determined by using a proxy variable based on the percentage of each household's total expenditures devoted to food. Descriptive statistic results indicated that the percentages of food insecure and secure households were $54 \%$ and $46 \%$ respectively. The two-sample t-test and proportion test results suggested that there
\end{abstract}

$\overline{\text { Department of Agribusiness Management, Faculty }}$ of Agricultural Sciences, Sabaragamuwa University of Sri Lanka, Belihuloya, Sri Lanka.

*maheshika@agri.sab.ac.lk

http://orcid.org/0000-0001-7130-400X

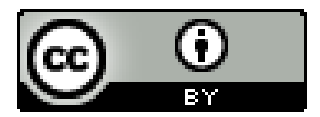

This article is published under the terms of the Creative

Commons Attribution 4.0

International License. which permits unrestricted use, distribution and reproduction in any medium provided the original author and source are credited. were significant differences of means in human capital variables between food secure and food insecure households. The results of the ordered logistic regression model revealed that if the household head was a female and educated, it would decrease the vulnerability of household to become food insecure, and if a household has a higher number of members who completed the secondary education, higher number of workers, lower young dependents and old dependents, food insecurity status of rural households in Sri Lanka would be reduced. In conclusion, the findings of this study support the empirical literature on the importance of human capital development in food insecurity status.

Keywords: Food insecurity index, Food security, Household food expenditure, Ordered logistic regression, Rural households.

\section{INTRODUCTION}

In recently, attention has been focused on means of eliminating food insecurity and hunger worldwide. The problem of food insecurity has wide diversity and multiple dimensions, which ranges from global to individual level. Despite the available resources and the efforts made by governments at different times, food insecurity remained one of the most crucial challenges to economic development (Dercon, 2004; Flores et al. 2005). Food security is a broad concept, encompassing issues related to the nature, quality and security of the food supply as well as issues of food access (Iram and Butt, 2004). It has 
been defined in different ways by different authors and organizations. However, the most widespread definition from FAO (2017) is considered as "food that is available to everyone at all times, that they have means of access to it, that it is nutritionally adequate in terms of quantity, quality and variety, and is acceptable within the given culture". In the absence of any of these conditions, it can be considered as food is insecure. The lack of food security, in other words, food insecurity can occur at different levels: household, regional and national. In the context of Sri Lanka, the Global Hunger Index (GHI) and the Global Food Security Index (GFSI) both rank Sri Lanka poorly in terms of food security (IPS, 2017). Based on the FAO (2017) statistics, the level of calorie deficit in Sri Lanka, 192 $\mathrm{Kcal} /$ capita/day on average in 2014-2016, is the highest in South Asia.

There has been a substantial concern about household food insecurity in middle and low-income countries (Ashby et al. 2016). Studying the multidimensional nature of food security has been an important topic (Gross et al. 2000; Magrini and Vigani, 2016). Efforts to overcome the development challenges posed by food insecurity essentially begin with accurate measurement of key indicators at the household level. This is due to the fact that identification of household behaviors relating to food access serves as a critical building block for the development of policies and programs for helping vulnerable populations, the effective targeting of assistance and the evaluation of impact (Smith and Subandoro, 2007).
Household food security is dependent on the physical availability of food, the ability of household to access the available food and the ability of individuals (particularly those susceptible to food deficits such as women, infants, children and disabled) to secure entitlement to it (Bouis and Hunt, 1999). A household is considered food insecure when its occupants live in hunger or fear of starvation. Beyene and Muche (2010) have stated in their study that interrelated causes of household food security and local responses during crisis require an analysis to move down to a household level. In Sri Lanka, the percentage of food-insecure households was reported in Household Food Insecurity Access Scale (HFIAS) score which was estimated to be 9.2 in 0 to 24 scale (DCS, 2014). Household food security in Sri Lanka has been linked with climate change (Esham et al. 2018). Further agricultural systems have shown to strengthen rural household-level food security (Thamilini et al. 2019; Galhena et al. 2013). The rural people were the most vulnerable to food insecurity as they have to deal with provisioning uncertainty in their food on a daily basis (Yasin, 2000). There are a limited number of publications available in the local context. Therefore, this study aims to examine the household food insecurity status of rural sector of Sri Lanka by addressing the research question on how food insecurity status depends on the socioeconomic characteristics of the household. Food insecurity in Sri Lanka has not been studied at the micro level from a representative sample. Mukarrama et al. (2013) measured the Aggregate Household 
Food Security Index (AHFSI) of ethnic fishing community in down south of Sri Lanka. Other studies have related food security with home gardens and agroforests, climate change but not with Household Income and Expenditure Survey (HIES) data for the rural cohort of Sri Lanka. This study attempted to find the impact of socioeconomic factors of rural households' food insecurity status which have not been studied yet.

\section{MATERIALS AND METHODS}

\section{Data Collection}

This study uses secondary data from the HIES conducted by the Department of Census and Statistics in Sri Lanka during the period of 2009/2010. The HIES survey has been conducted over a period of 12 months (from July 2009 to June 2010). The data set comprises 19,958 households and it represents the rural, urban and estate sector areas on the national level. The data is on demographic and socioeconomic variables and includes detailed information about the income and expenditure of each household. This data-set is considered as the most representative household-level data in Sri Lanka.

Table 1. Categorization of food insecurity levels

\section{Analytical Techniques and Variable Measurement}

Based on a critical review of the literature, the following analytical technique and explanatory variables were theorized to have an influence on household food insecurity (Table 1). In achieving the objective of identifying the determinants of rural household food insecurity, the analysis was carried out in two stages. In the first stage, the food insecurity index was determined and in the second stage, ordered logistic regression model was used to estimate the food insecurity status of the households as a function of a set of independent variables.

\section{Determination of Household Food Insecurity Index}

The percentages of expenditure on food were used as a guideline to determine the food insecurity status of each household (Smith and Subandoro, 2007). According to Smith and Subandoro (2007), households that spent a large proportion of their income on food were vulnerable to food deprivation because, regardless of their current food consumption status, if they were to experience a reduction in the income it would likely to be accompanied by a

\begin{tabular}{llc}
\hline Food Insecurity Level & Food Expenditure Share & Code \\
\hline Very high food insecurity level & $>75 \%$ & 1 \\
High food insecurity level & Between 65 to 75\% & 2 \\
Medium food insecurity level & Between 50 to 65\% & 3 \\
Low food insecurity level & Lower than 50\% & 4 \\
\hline
\end{tabular}

Source: Smith and Subandoro (2007). 
reduction in food consumption or the quality of food eaten (Table 1). Moreover, a study reported by COCA (2006) and the U.S. Department of Labour (2006) revealed that the poorest households in the world spent more than $75 \%$ of their income on food. Households in the richest countries, such as the United States and Canada, spent less than $15 \%$ of their expenditures on food. By considering all those facts this study used following guidelines to measure the food insecurity status of the rural Sri Lankan households.

The food insecurity index was measured by using a proxy variable based on the percentage of each household's total expenditures devoted to food. To calculate the measure, each household's monthly expenditures on food were matched at the household level with their total

Table 2. Description of variables expenditures. The formula for calculating the percentage of expenditures on food is, Percentage of expenditure on food $=\left(\frac{\text { Expenditure on food }}{\text { Total household expenditure }}\right) \times 100$

(Eq. 1)

Based on the household food insecurity status an ordered logistic regression model was estimated to identify the determinants of food insecurity among rural households. The implicit form of the model was expressed as,

$$
Z_{i}=\beta X_{i}+u_{i}
$$

where; $Z_{i}$ is the food insecurity status of $i$ th household, $\beta$ is vector of the parameter estimates, $X_{i}$ is vector of explanatory variables, $u_{i}$ is the error terms. The dependent variable and independent variables included in the model are shown in Table 2.

\begin{tabular}{ll}
\hline Variable & Units/Description \\
\hline The food insecurity status of $i^{\text {th }}$ household & $\begin{array}{l}\text { Food insecurity status of } i^{\text {th }} \text { household which take } \\
\text { values 1 for very high food insecurity level, } 2 \text { for } \\
\text { high food insecurity level, } 3 \text { for medium food } \\
\text { insecurity level, } 4 \text { for low food insecurity level } \\
\text { Years }\end{array}$ \\
$\begin{array}{l}\text { Age of the household head } \\
\text { Gender of the household head }\end{array}$ & $\begin{array}{l}\text { Number of years of education } \\
\text { Education level of the household head }\end{array}$ \\
Total household size & Number \\
Number of family members who complete & Number \\
their secondary level education & \\
Total number of workers in a household & Number \\
Dependency ratio & Number \\
Agriculture land ownership & Dummy where1= land owned, 0=otherwise \\
Livestock ownership & Dummy where1= Livestock owned, $0=$ otherwise \\
Time taken to go to nearest town (mins) & Minutes \\
Agricultural income & Value in Rs. \\
Non-agricultural income & Value in Rs. \\
\hline
\end{tabular}




\section{RESULTS AND DISCUSSION}

As per the descriptive statistics, among the percentages of food insecure and secure households, $6.85 \%$ with very high levels of food insecurity, $14 \%$ with highlevel food insecurity, $33 \%$ with medium level food insecurity and $46 \%$ with lowlevel food insecurity were found (Table 3). This suggests that roughly $20 \%$ of the rural households are in a dire need of assistance to overcome the food insecurity levels. About $33 \%$ is just above the $50 \%$ threshold point. The severe food-insecure households may need prolonged support over a considerable period of time. Therefore, the assistance to these distinct groups should be provided in different approaches.

Table 4 presents the summary statistics of the independent variables. The variables are helpful to observe significant differences among food insecure and secure-households including household characteristics such as education level of the household head, number of workers, number of young dependents, number of old dependents and number of members in the family who have done Advanced Level (A/L) examination and who are above age 15 (Table 5).

Table 3. Percentage of households at different food insecurity levels

\begin{tabular}{llc}
\hline Food insecurity Level & $\begin{array}{l}\text { Food Expenditure } \\
\text { Share }\end{array}$ & $\begin{array}{l}\text { Percentage of } \\
\text { Households }\end{array}$ \\
\hline Very high food insecurity level, 1 & $>75 \%$ & $6.85 \%$ \\
High food insecurity level, 2 & Between 65 to 75\% & $14.05 \%$ \\
Medium food insecurity level, 3 & Between 50 to 65\% & $33.09 \%$ \\
Low food insecurity level, 4 & Lower than 50\% & $46.01 \%$ \\
\hline Total number of rural households $(N)=12,489$ &
\end{tabular}

Table 4. Summary statistics of independent variables

\begin{tabular}{llllll}
\hline Variable name & Mean & Std. dev. & Min. & Max. & $\begin{array}{c}\text { Std. } \\
\text { Err. }\end{array}$ \\
\hline Age of the household head & 50.97 & 14.00 & 15 & 99 & 0.126 \\
$\begin{array}{l}\text { Education level of the household head } \\
\text { Household size }\end{array}$ & 8.63 & 3.98 & 1 & 16 & 0.036 \\
$\begin{array}{l}\text { Number of family members completed } \\
\text { secondary education }\end{array}$ & 0.07 & 0.31 & 0 & 4 & 0.015 \\
Number of workers in a household & 1.42 & 0.85 & 0 & 7 & 0.003 \\
$\begin{array}{l}\text { Dependency ratio } \\
\text { Time to nearest town (mins) }\end{array}$ & 0.77 & 0.78 & 0 & 9 & 0.008 \\
Agricultural income (annual) & 34.04 & 24.45 & 1 & 180 & 0.007 \\
Non-agricultural income(annual) & 8761.94 & 54104.54 & 0 & $2,250,000$ & 487.772 \\
\hline
\end{tabular}

Note: Gender of the household head, agriculture land ownership and Livestock ownership variables were dummy variables hence they are not presented in the table. 
Results indicated that all most all socioeconomic characteristics of the food secure and food insecure-households were significantly different except the mean age of the household head. It denoted that most of the human capital variables were biased towards food secure households. It can be inferred that educated youth may play a role in food security status.

\section{Econometric Analysis}

Table 6 shows the coefficients of the ordered logistic regression which was run to examine the determinants of household food insecurity in rural Sri Lankan households.
Rural household-level food insecurity status has reduced, i.e. they have become food secure with the factors such as lower household size, lower livestock ownership, male household head, higher education, higher family members with completed $\mathrm{A} / \mathrm{L}$ education, a higher number of workers, higher dependency ratio, higher agricultural and non-agricultural income. Rural food insecurity status was not significantly affected by the ownership of Agricultural land. But it has a negative relationship with the improvement of food insecurity status. This may be because, in rural society, people consume very diverse fruits and vegetables through different sources. Some consume through their cultivation and some other collect from chena, wild etc..

Table 5: Comparison of food secure and insecure household characteristics

\begin{tabular}{|c|c|c|c|}
\hline Variable & $\begin{array}{l}\text { Food Insecure } \\
\text { (Mean) }\end{array}$ & $\begin{array}{l}\text { Food Secure } \\
\text { (Mean) }\end{array}$ & P-value \\
\hline Age of the household head ${ }^{+}$ & 50.968 & 50.963 & 0.984 \\
\hline $\begin{array}{l}\text { Education (schooling years) of the household } \\
\text { head }^{+}\end{array}$ & 7.952 & 9.421 & $0.000 *$ \\
\hline Agricultural income (Rs./annual) $^{+}$ & 6515.16 & 11398.55 & $0.000 *$ \\
\hline Non-agricultural income (Rs./annual) $^{+}$ & 7968.893 & 65435.03 & $0.048 *$ \\
\hline Gender of the household head ${ }^{++}$ & - & - & $0.000 *$ \\
\hline Marital Status of the Household head ${ }^{++}$ & - & - & $0.000 *$ \\
\hline Total Household size ${ }^{++}$ & 4.195 & 4.236 & $0.025^{*}$ \\
\hline The number of workers over age $15^{++}$ & 1.366 & 1.475 & $0.000 *$ \\
\hline Number of young dependents ${ }^{++}$ & 1.151 & 1.039 & $0.000 *$ \\
\hline Number of old dependents ${ }^{++}$ & 0.517 & 0.569 & $0.004 *$ \\
\hline Number of males above $\mathrm{A} / \mathrm{L}^{++}$ & 0.012 & 0.054 & $0.019 *$ \\
\hline Number of Females above $\mathrm{A} / \mathrm{L}^{++}$ & 0.019 & 0.062 & $0.016^{*}$ \\
\hline Number of Males above $15^{++}$ & 1.517 & 1.593 & $0.000 *$ \\
\hline Number of Females above $15^{++}$ & 1.593 & 1.664 & $0.001 *$ \\
\hline
\end{tabular}

*Significant at $5 \%$ significance level $;{ }^{+}$denotes $t$ tests, ${ }^{++}$denotes proportion test 
In rural Sri Lanka, household-level food security has been strengthened through wild-collected underutilized crops (Bandula et al. 2016) as well as contributions from (Krishnal et al. 2012). Further, home gardens have been traditionally associated with women and this posits a connection with women and food security (Kularathne et al. 2019). Bandara et al. (2014), too have concluded that Sri Lankan agriculture has played a role in decreasing food insecurity status, inter alia.

Gender was positively correlated with low food insecurity level. Male headed households were more likely to be food secure and female-headed households were more vulnerable to food insecurity. A study conducted by Carter et al. (2010) has looked into the determinants of food insecurity in New Zealand households with special emphasis on gender differences. It suggested that prevalence of food insecurity was high among females compared to males.

Higher levels of education have led to the low level of food insecurity in rural households. Educated households may be earning more or have better avenues of managing resources, thereby reducing food insecurity. Total household size negatively and significantly correlated with low level of food insecurity.

Table 6. Results of the ordered logistic regression

\begin{tabular}{lll}
\hline Variable & Coefficient & Std. Err. \\
\hline Age & -0.001 & 0.002 \\
Gender & $0.295^{* * *}$ & 0.050 \\
Education & $0.091^{* * *}$ & 0.006 \\
Household size & $-0.058^{* * *}$ & 0.015 \\
Number of family members & $0.833^{* * *}$ & 0.095 \\
completed secondary education & & \\
Number of workers & $0.183^{* * *}$ & 0.027 \\
Dependency ratio & $0.145^{* * *}$ & 0.023 \\
Agriculture land ownership & -0.056 & 0.052 \\
Livestock ownership & $-0.399^{* * *}$ & 0.058 \\
Time to nearest town (mins) & 0.0001 & 0.001 \\
Agricultural income & $2.09 \mathrm{e}-06^{* * *}$ & 0.001 \\
Non-agricultural income & $5.40 \mathrm{e}-06^{* * *}$ & $1.08 \mathrm{e}-06$ \\
\hline /cut1 & -1.573 & 0.131 \\
/cut2 & -0.275 & 0.128 \\
/cut3 & 1.305 & 0.129 \\
\hline $\mathrm{N}=12,384$, Pseudo $\mathrm{R}^{2}=0.0383$ & Wald chi ${ }^{2}(12=575.99$ \\
Log pseudo likelihood = -4447278.7 & Prob> chi ${ }^{2}=0.0000$ \\
\hline ***Significant at 1\% significance level & \multicolumn{2}{l}{}
\end{tabular}


The number of family members who completed secondary education positively correlated with low level of food insecurity. This implies that, when there are more mouths to feed, more money needs to be spent on food purchases, but, when there are many adult children, either they can work in the farm or off-farm and bring more income. Thereby their presence reduces the likelihood of food insecurity at the household level.

The low level of food insecurity was negatively correlated with agricultural land ownership and ownership of livestock. Owning more arable land and livestock could reduce the risk of food insecurity by diversifying income. Further, households get access to eggs and milk through livestock, even sometimes meat. They are all good protein sources and also provide essential micronutrients. Feleke et al. (2005) studied household food security of rural Ethiopians especially including demand-side factors and supply-side factors. Similarly, we also used some factors like land ownership, livestock ownership and access to town. They concluded that supply-side factors were more powerful in determining household food security compared to demand-side factors.

Another startling finding was the dependency ratio, where low level of food insecurity positively correlated with the dependency ratio. But the hypothesis is that when there is a higher dependency ratio a positive likelihood is expected with food insecurity. One plausible reason could be that when there are dependents, they consume less food compared to adults, though they might ask for other food commodities, like non-essentials. But when dependency ratio is low, the family needs more food to prepare and it might be costly. The exceptional case could be when older people are there, but still, then they consume less of food.

Cut 1 , cut 2 , and cut 3 were ancillary parameters that are known as the threshold or cut points. They were used to differentiate the adjacent levels of the response variable. Cut 1 was the estimated cut point on the latent variable used to differentiate very high level of food insecurity from the other three categories of food insecurity when values of the predictor variables were evaluated at zero. Rural households who had a value of -1.573 or less on the underlying latent variable that gave rise to our food insecurity variable were classified as very high food insecurity. Cut 2 was the estimated cut point on the latent variable used to differentiate very high and high food insecurity from low and medium food insecurity levels. Rural households whose threshold fall between 1.573 and -0.27499 on the underlying variable was classified as high food insecure group. Rural households whose threshold fall between -0.274 and 1.305 on the underlying latent variable, were classified as medium food insecure and those who were above 1.305 were classified as lower food insecure group.

Marginal effects of the ordered logit regression (Table 7 ) reveals that being a male is associated with being $1.6 \%$ less 
likely to be in very high food insecurity cohort, $2.8 \%$ less likely to be associated with high food insecurity, $3.0 \%$ less likely to be associated with medium insecurity and $7.3 \%$ more likely to be associated with lower food insecurity. Similarly, a rise in one unit of education is associated with being $0.5 \%$ less likely to be in very high food insecure group, $0.8 \%$ less likely to be in high food insecure group and $1.0 \%$ less likely to be in medium food insure group. Meanwhile $2.3 \%$ more likely to be associated with lower food insecurity. When total household size increases by one unit, it is associated with $0.3 \%$ more likely to be in the very high food insecure category, $0.5 \%$ more likely to be in the high food insecure category, $0.6 \%$ more likely to be in the medium food insecure category, and $1.4 \%$ less likely to be in the lower food insecure category. This is in line with the hypothesis.
The number of workers in the household and number of adults above $\mathrm{A} / \mathrm{L}$ education also determines household food security positively. They improve the incidence of household food insecurity. One-unit increase in total workers in the family, associated with being $0.9 \%$ less likely to very high food insecure, $1.6 \%$ less likely to be high food insecure, $2.0 \%$ less likely to be in medium food insecurity, and $4.6 \%$ more likely to be in the lower food insecurity group. The dependency ratio also shows a similar trend. Though agriculture income and non-agricultural income improves the food insecurity conditions, their coefficients and marginal effects are rather very small.

Although the findings of this study are supported by many literatures, there are some studies that resulted in contrast findings as well. Ngema et al. (2018),

Table 7. Marginal effects of the ordered logit regression

\begin{tabular}{lllll}
\hline Variable & $\begin{array}{l}\text { Very high } \\
\text { food } \\
\text { insecurity }\end{array}$ & $\begin{array}{l}\text { High food } \\
\text { insecurity }\end{array}$ & $\begin{array}{l}\text { Medium } \\
\text { food } \\
\text { insecurity }\end{array}$ & $\begin{array}{l}\text { Low food } \\
\text { insecurity }\end{array}$ \\
\hline Age & 0.000 & 0.000 & 0.000 & -0.000 \\
Gender & -0.016 & -0.028 & -0.030 & 0.073 \\
Education & -0.005 & -0.008 & -0.010 & 0.023 \\
Household size & 0.003 & 0.005 & 0.006 & -0.014 \\
Number of family members & -0.041 & -0.075 & -0.092 & 0.208 \\
completed secondary education & & & & \\
Number of workers & -0.009 & -0.016 & -0.020 & 0.046 \\
Dependency ratio & -0.041 & -0.013 & -0.016 & 0.036 \\
Agriculture land ownership & 0.003 & 0.005 & 0.006 & -0.014 \\
Livestock ownership & 0.022 & 0.039 & 0.038 & -0.099 \\
Time to nearest town (mins) & $-7.35 \mathrm{e}-06$ & -0.000 & -0.000 & 0.000 \\
Agricultural income & $-1.03 \mathrm{e}-07$ & $-1.88 \mathrm{e}-07$ & $-2.31 \mathrm{e}-07$ & $5.23 \mathrm{e}-07$ \\
Non-agricultural income & $-2.67 \mathrm{e}-07$ & $-4.87 \mathrm{e}-07$ & $-5.97 \mathrm{e}-07$ & $1.35 \mathrm{e}-06$ \\
\hline
\end{tabular}


looks at the determinants of household food security status among a group of people who were involved in a beneficiary program through home garden ownership. It revealed that education, receiving support, and participation in the intervention program were positively associated with household food security. Contrastingly, it showed a negative association with income and access to credit. But in our analysis, education and income all are positively correlated with food security.

Findings concluded that the incidence of food insecurity was negatively correlated with agricultural and non-agricultural income. This study did not examine the type of income arrangements. But, Faridi and Wadood (2010) report that in Bangladesh, daily wage earners and monthly salary earners are worse off in terms of food security compared to the ones who are selfemployed, in agriculture or non-agriculture sector.

Similarly Giri et al. (2006) found that the prevalence of food insecurity was $36 \%$ in Tabriz, Iran. Food insecurity was positively associated with family size and negatively associated with income, education, Job status of the household head. Food insecure households consumed more bread and potatoes and less rice, vegetables, fruits, red meat, and dairy products. This finding suggests that depending on the cultural status also food insecurity could differ. Further, food-insecure households limit their consumption to one or two food products, whereas food secure households diversify their consumption patterns.

\section{CONCLUSION}

This study examined the determinants of food insecurity in the context of rural households in Sri Lanka. Among the samples, $22 \%$ were at high levels of food insecurity and $33 \%$ were just above the threshold point. First, a significant difference in the means was observed in selected socio-economic factors between the food secure and food-insecure households. Though the results did not show any bias towards gender, based on the ordered logit regression, the household head, being higher educated and female could affect to decrease the vulnerability of households to become food insecure. If a household have a higher number of members who completed the A/L, a higher number of workers, lower young dependents and old dependents, food insecurity status of households might reduce. Rural household-level food insecurity status has reduced with lower household size, and lower livestock ownership.

The results support the empirical literature on the importance of human capital development in food insecurity status and this will help for policymakers when formulating policies to reduce household food insecurity. The study limits its scope to rural households, but this can be extended to the estate sector and the urban sector as well. Certain variables may provide different results compared to the rural context. However, it is clear that for food insecurity there are human capital variables as well as assets ownership 
variables that play important roles. But these can be moderated through the institutions and government interventions.

\section{REFERENCES}

Ashby, S., Kleve, S., McKechnie, R. and Palermo, C. (2016). Measurement of the dimensions of food insecurity in developed countries: a systematic literature review. Public Health Nutrition, 19(16): 2887-2896.

Bandara, E. G. C. D., Jayasinghe-mudalige, U. K., Udugama, J. M. M., Attanayake, A. M. C. M. and Edirisinghe, J. C. (2014). Has the food and agriculture sector played its intended role in socioeconomic development of Sri Lanka? An empirical investigation. Journal of Agricultural Sciences-Sri Lanka, 9(2).

Bandula, A., Jayaweera, C., De Silva, A., Oreiley, P., Karunarathne, A. and Malkanthi, S. H. P. (2016). Role of underutilized crop value chains in rural food and income security in Sri Lanka. Procedia Food Science, 6: 267270.

Beyene, F. and Muche, M. (2010). Determinants of food security among rural households of central Ethiopia: an empirical analysis. Quarterly Journal of International Agriculture, 49(8922016-65219): 299-318.

Bouis, H. and Hunt, J. (1999). Linking food and nutrition security: past lessons and future opportunities, Asian Development Review, 17(1/2): 168-213.

Carter, K. N., Lanumata, T., Kruse, K. and Gorton, D. (2010). What are the determinants of food insecurity in New Zealand and does this differ for males and females? Australian and New Zealand Journal of Public Health, 34(6): 602-608.

COCA (Canada's Office of Consumer Affairs) (2006). The consumer trends report. Canada's Office of Consumer Affairs, Ottawa, Ontario.

Department of Census and Statistics (2014). Annual report, Sri Lanka

Dercon, S. (2004). Growth and shocks: evidence from rural Ethiopia. Journal of Development Economics, 74(2): 309329.

Esham, M., Jacobs, B., Rosairo, H. S. R. and Siddighi, B. B. (2018). Climate change and food security: a Sri Lankan perspective. Environment, Development and Sustainability, 20(3): 1017-1036. Retrieved from https://doi.org/10.1007/s10668-0179945-5

Faridi, R. and Wadood, S. (2010). An econometric assessment of household food security in Bangladesh. The Bangladesh Development Studies, 33(3): 97-111. Retrieved from www.jstor.org/stable/23339854

Feleke, S. T., Kilmer, R. L. and Gladwin, C. H. (2005). Determinants of food security in southern Ethiopia at the household level. Agricultural Economics, 33(3): 351-363.

Flores, M., Khwaja, Y. and White, P. (2005). Food security in protracted crises: building more effective policy frameworks. Disasters, 29: 25-51.

Food and Agricultural Organization (FAO) of the United Nations (2017). The state of food and agriculture, Rome, Italy

Galhena, D. H., Freed, R. and Maredia, K. M. (2013). Home gardens: a promising approach to enhance household food security and wellbeing. Agriculture \& Food Security, 2(1): 8.

Giri D. S., Mahboub S. A., Toutounchi H. and Ostad-Rahimi, A. R. (2006). Determinants of food insecurity: A cross sectional study in Tabriz, Journal of Ardabil University of Medical Sciences, 6(3): 233-239. 
Gross, R., Schoeneberger, H., Pfeifer, H. and Preuss, H. J. (2000). The four dimensions of food and nutrition security: definitions and concepts. $S C N$ News, 20(20): 20-25.

Institute of Policy Studies (IPS), (2017). Annual report, 2017, Sri Lanka

Iram, U. and Butt, M. S. (2004). Determinants of household food security: an empirical analysis for Pakistan. International Journal of Social Economics, 31(8): 753-766.

Krishnal, S., Weerahewa, J. and Gunaratne, L. H. P. (2012). Role of home gardens in achieving food security in Batticaloa district, Sri Lanka. In International conference on economics and finance research IPEDR. IACSIT Press, Singapore.

Kularathne, T. M., Sivashankar, P. and Wekumbura, W. G. (2019). Measuring the success of women led "dry zone home gardening" program with organic amendments in Sri Lanka. Agricultural Socio-Economics Journal, 19(3): 191203.

Magrini, E. and Vigani, M. (2016). Technology adoption and the multiple dimensions of food security: the case of maize in Tanzania. Food Security, 8(4): 707-726.

Mukarrama, M. M. F., Udugama, J. M. M., Jayasinghe-mudalige, U. K., Ikram, S. M. M. and Dissanayake, S. N. (2013). Assessing the household food security of marine fisheries sector in Sri Lanka: case of Muslim fishing community in the Beruwala divisional secretariat division. Sri Lanka Journal of Aquatic Sciences, 15.

Ngema, P. Z., Sibanda, M. and Musemwa, L. (2018). Household food security status and its determinants in Maphumulo local municipality, South Africa. Sustainability, 10(9): 3307.

Smith, L. C. and Subandoro, A. (2007). Measuring food security using household expenditure surveys (Vol. 3). Intl Food Policy Res Inst. http://dx.doi.org/10.2499/0896297675

Thamilini, J., Wekumbura, C., Silva, R. R., Mohotti, J., Kumara, A., Kudagammana, S. T. and Frossard, E. (2019). Organized homegardens contribute to micronutrient intakes and dietary diversity of rural households in Sri Lanka. Frontiers in Sustainable Food Systems, 3(94).

U.S. Department of Labor. (2006). Consumer expenditures in 2004. U.S. Bureau of Labor Statistics Report 992. Washington, D.C.

Yasin, M. A. (2000). An investigation into food security situation in rain-fed areas of district Rawalpindi (Unpublished M. Sc. thesis), Department of Agricultural Economics. University of Agriculture, Faisalabad, Pakistan. 